\title{
Comunicación
}

\section{Reporte de caso: tenosinovitis traumática de la vaina sinovial tarsiana en un caballo Pura Raza Española}

\author{
Case report: traumatic tenosynovitis of the tarsal synovial sheath in a \\ Purebred Spanish Horse
Lucas Giraldo Botero' ${ }^{2}$, Santiago Madrigal Cadavid ${ }^{1}$, Renso Sneider Gallego Rodriguez ${ }^{1,3}$

\section{RESUMien}

Se reporta el caso de un paciente equino Pura Raza Española (PRE), macho de 4.5 años que llega por motivo de consulta ante un aumento de tamaño histórico de tres meses en la región tarsiana del miembro posterior izquierdo. Con base al examen clínico y la evaluación radiológica y ultrasonográfica se le diagnosticó tenosinovitis traumática de la vaina sinovial tarsiana. Fue tratado con aplicación intrasinovial con antiinflamatorios esteroidales, sulfato de atropina y ácido hialurónico, además, de lavados sinoviales con dimetil sulfoxido (DMSO) a nivel intrasinovial y fisioterapia basada en laser y ultrasonido terapéutico. El paciente respondió satisfactoriamente al tratamiento instaurado.

Palabras clave: ecografía, efusión sinovial, equino, tenosinovitis, vaina tarsiana

\section{AbStract}

The case of a Purebred Spanish Horse (PRE) patient, 4.5-year-old male who comes for consultation due to a historical increase of three months in the tarsal region of the left hind limb is reported. Based on the clinical examination and radiological and ultrasonographic evaluation, it was diagnosed with traumatic tenosynovitis of the tarsal

\footnotetext{
${ }^{1}$ Grupo de Investigación GINVER, Corporación Universitaria Remington, Medellín, Colombia

${ }^{2}$ North Carolina State University, USA

${ }^{3}$ E-mail: renso.gallego@uniremington.edu.co
}

Recibido: 26 de agosto de 2019

Aceptado para publicación: 15 de mayo de 2020

Publicado: 11 de agosto de 2020 
synovial sheath. The horse was treated with intrasynovial application with steroidal antiinflammatory drugs, atropine sulfate and hyaluronic acid, in addition to synovial lavages with dimethyl sulfoxide (DMSO) at intra-synovial level and physiotherapy based on laser and therapeutic ultrasound. The patient responded satisfactorily to the established treatment.

Key words: ultrasound, synovial effusion, equine, tenosynovitis, tarsal sheath

\section{INTRODUCCIÓN}

La vaina sinovial es una delgada pared de doble capa con morfología tubular, llena de líquido sinovial, encargada de recubrir las estructuras tendinosas para proteger y disminuir su fricción al realizar movimientos de extensión y flexión, durante el paso por una estructura ósea (Ashdown y Done, 2011). La vaina tarsiana en el equino se encuentra en el aspecto medial del tarso y comienza entre 5 y $8 \mathrm{~cm}$ proximales al maléolo medial de la tibia hasta el tercio proximal del metatarso. En caballos, de manera general se establece que tiene una longitud que varía entre 21 y 32 $\mathrm{cm}$ y un volumen estimado de 20 a $50 \mathrm{ml}$ (Budras et al., 2008). Incluye al tendón flexor digital profundo (TFDP) del miembro posterior, ya que cursa sobre el sustentaculum tali en el aspecto medial del tarso (Budras et al., 2008).

La tenosinovitis traumática de la vaina sinovial tarsiana es una patología que se caracteriza por generar aumento de tamaño a nivel medial y en ocasiones lateral del tarso. En general se describe como la inflamación del tendón y la vaina que lo recubre, que genera la distensión de la vaina tendinosa debido a la efusión sinovial (Baxter, 2011). Entre las causas de esta patología se puede mencionar la idiopática, con efusión dentro de la vaina tarsiana, pero sin aparente claudicación o limitaciones de rendimiento; traumática, la cual presenta inflamación del aspecto medial del tarso, usualmente con grado de claudicación de 2-3/5 y positivo a la prueba de flexión del tarso; y la séptica, donde el caballo no soporta su peso y efusión difusa de todo el tarso y dolor a la presión digital a nivel de la vaina (Ross y Dyson, 2003).

El diagnóstico se realiza mediante un examen clínico ortopédico, donde la flexión del tarso y el bloqueo anestésico intrasinovial de la vaina generalmente resultan positivos. Además, ayudas diagnósticas como las placas radiográficas y la ultrasonografía (Butle et al., 2008). El tratamiento más común incluye infiltraciones intrasinoviales de antiinflamatorios como esteroides y ácido hialurónico, además vendajes de sudor y reducción del ejercicio (Ross y Dyson, 2003). La efusión idiopática persistente también puede ser tratada con atropina intrasinovial. En los caballos con fracturas, exostosis $\mathrm{u}$ osteomielitis del sustentaculum tali se puede hacer un procedimiento quirúrgico basado en tenoscopía de la vaina sinovial tarsiana (Baxte et al., 2011). Teniendo en cuenta lo mencionado, el objetivo de este caso clínico fue describir el abordaje diagnóstico clínico y terapéutico de un paciente equino con tenosinovitis traumática de la vaina sinovial tarsiana.

\section{Descripción del Caso}

Un paciente equino macho Pura Raza Española (PRE) de 4.5 años y $450 \mathrm{~kg}$ de peso es remitido para su evaluación al Centro de Ortopedia Equina Especial Vet, en Medellín, Colombia. Se reporta como motivo de consulta un aumento de tamaño a nivel del tarso con un periodo de evolución de tres 

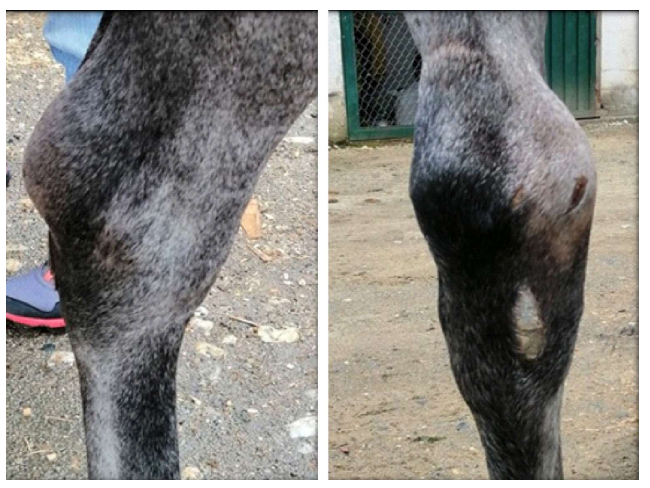

Figura 1. Equino macho PRE de 4.5 años. Se observa efusión de la vaina sinovial tarsiana en una vista lateral y plantar, Aumento de tamaño de la región con consistencia líquida a la palpación

meses. No se reporta trauma a nivel de los miembros posteriores, $y$ se describe tratamiento médico mediante aplicación de antiinflamatorios de tipo esteroidal e incisión distal a la vaina para producir drenaje.

\section{Evaluación Clínica Ortopédica}

El paciente no muestra claudicación, pero presenta aumento de tamaño con efusión a nivel medial y lateral del tarso del miembro posterior izquierdo y pruebas de flexión distal y proximal negativas. No presenta dolor a la palpación (Figura 1). Basado en la evaluación ortopédica se describen como diagnósticos diferenciales tenosinovitis idiopática, tenosinovitis traumática, tenosinovitis séptica y fractura del sustentuculum tali. Como plan diagnóstico se propone realizar evaluación radiológica digital y evaluación ultrasonográfica del tarso en el miembro posterior izquierdo. Así mismo, sinoviocentesis de la vaina sinovial tarsiana con el fin de hacer una evaluación macroscópica del líquido sinovial de la misma.

\section{Evaluación Radiológica Digital}

Se realizó la evaluación radiológica digital del tarso afectado considerando las proyecciones radiológicas de latero medial, dorso plantar y lateral, plantar medial oblicua y lateral dorso medial oblicua. Todas las estructuras evaluadas se estuvieron dentro de los límites radiográficos normales.

\section{Evaluación Ultrasonográfica}

Se hizo la evaluación ultrasonográfica del tendón flexor digital profundo (TFDP) en todo su recorrido por la vaina sinovial tarsiana, realizando imágenes transversales y longitudinales (Figura 2). Se observa efusión intrasinovial y coágulos de fibrina de la vaina sinovial tarsiana, así como áreas hipoecoicas a nivel de la cabeza medial del TFDP. Con base a estas imágenes, se da como diagnóstico definitivo la tenosinovitis traumática de la vaina sinovial tarsiana del miembro posterior izquierdo.

\section{Terapéutica}

Se realiza tratamiento médico ortopédico basado en infiltración intrasinovial (antiinflamatorios esteroidales, ácido hialurónico y sulfato de atropina) (Figura 3a). Se realiza sedación del paciente con xilacina $(0.5 \mathrm{mg} / \mathrm{kg})$ vía endovenosa. Luego, se realiza infiltración intrasinovial con acetato triamcinolona (12 $\mathrm{mg}$ dosis total), acetato de betametasona ( $8 \mathrm{mg}$ total), ácido hialurónico (40 $\mathrm{mg}$ dosis total), amikacina (100 mg total)


Figura 2. Equino macho PRE de 4.5 años. Vista ultrasonográfica del tendón flexor digital profundo. Se observa aumento del volumen del líquido sinovial en la vaina tarsiana $(*)$ y coágulo de fibrina de aspecto ecogénico con ecotextura heterogénea (flecha) 
(a)

(b)
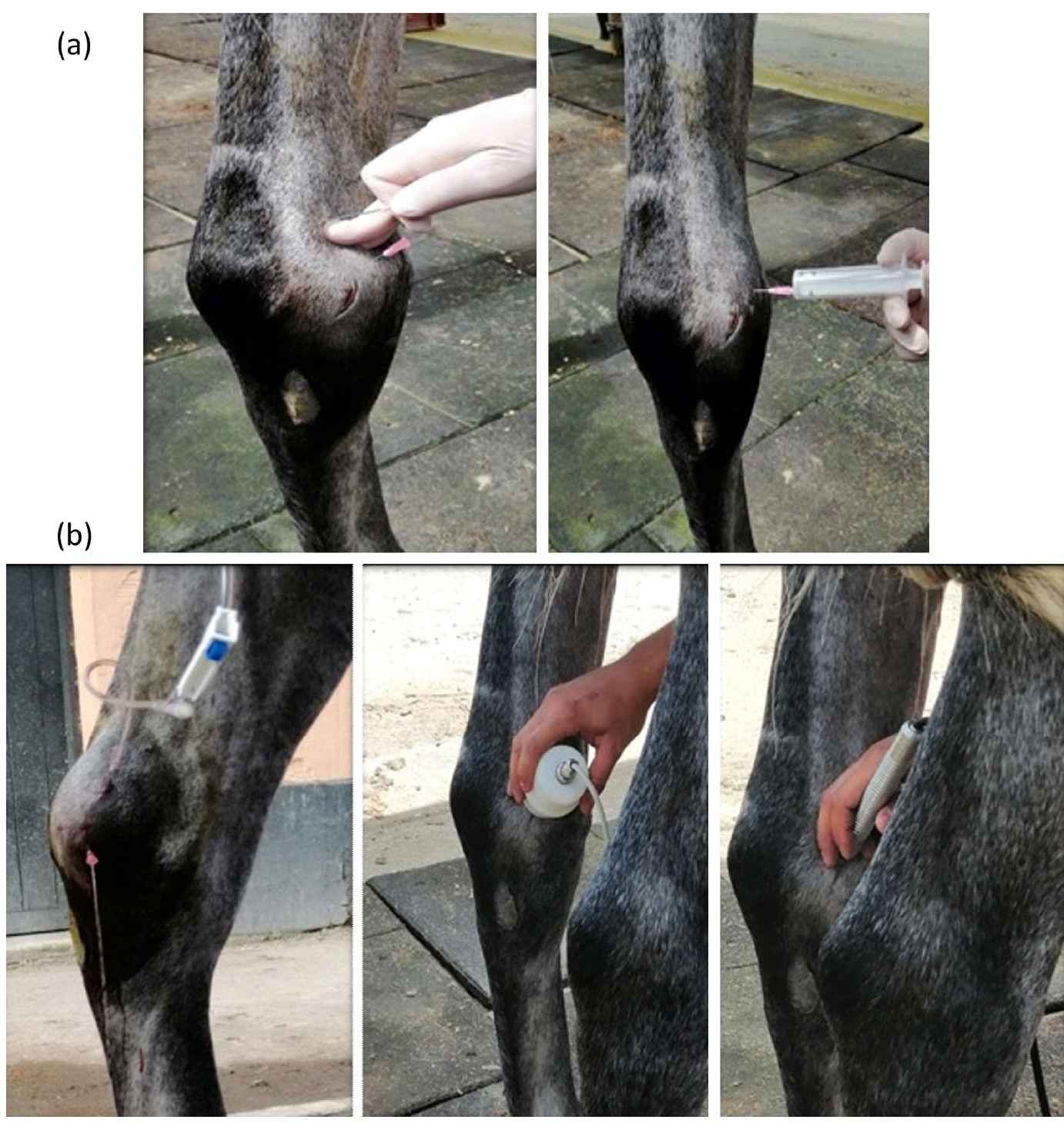

Figura 3. Equino macho PRE de 4.5 años con tenosinovitis traumática de la vaina sinovial tarsiana. (a) Infiltración de la vaina tarsiana por medio de un abordaje medial; (b) Terapia combinada de lavados intrasinoviales con dimetil sulfóxido - DMSO (diluido al 10\% en 100 ml de solución Hartman), laser y ultrasonido terapéutico

y sulfato de atropina (4 mg total). Además, se realizan vendajes de sudor con pomadas calientes y antiinflamatorias por cinco días y se restringe el ejercicio por una semana. Posteriormente, se empieza a ejercitar en forma progresiva (caminata al tiro durante de 10 minutos y en la tercera semana trabajo montado caminando durante 20 minutos al día).
El paciente tuvo una disminución significativa de la efusión de la vaina sinovial tarsiana del $70 \%$ posterior a la infiltración intrasinovial y a el ejercicio recomendado. Sin embargo, luego de dos semanas de trabajo exigente vuelve a presentar efusión intrasinovial. En esta ocasión, se implementa un nuevo tratamiento médico ortopédico basado 
en lavados de la vaina sinovial tarsiana, infiltración intrasinovial (antiinflamatorios esteroidales, ácido hialurónico y sulfato de atropina). Para esto, instaura una terapia nueva, según lo propuesto por Archer (2004). Se realiza la sedación del paciente con xilacina $(0.5 \mathrm{mg} / \mathrm{kg})$ vía endovenosa y se hacen lavados intrasinoviales con dimetil sulfóxido DMSO (diluido al 10\% en $100 \mathrm{ml}$ de solución Hartman) por 3 días. Luego se realiza infiltración intrasinovial con acetato triamcinolona (12 mg dosis total), acetato de betametasona ( $8 \mathrm{mg}$ total), ácido hialurónico (40 mg dosis total), amikacina (100 mg total) y sulfato de atropina (4 mg total).

Se restringe el ejercicio por dos semanas, para luego comenzar a trabajar siguiendo la rutina anterior. Además, se implementa fisioterapia basada en laser y ultrasonido terapéutico realizando un efecto fibrinolítico, regeneración del TFDP y de disminución de efusión (Figura 3b). Luego de nueve semanas, el paciente presenta una mejoría del $90 \%$; asimismo, se le hizo una evaluación ultrasonográfica evidenciándose disminución del grado de efusión intrasinovial y mejoría significativa en la arquitectura del parénquima del TFDP.

\section{Discusión}

La distensión unilateral de la vaina del tarso generalmente es atribuida a un traumatismo (Minshall y Wright, 2012); Cauvin (2003) afirmó que la distensión de la vaina sinovial puede ser de causa idiopática, traumática, secundaria a lesiones del tendón flexor digital profundo, o relacionada a sepsis sinovial. La causa inicial por la cual se dio la presentación de la efusión sinovial es incierta, aunque posiblemente pudo estar relacionada a un traumatismo en la región tarsiana (Barr et al. (2005); sin embargo, no se encontró indicios clínicos de esto.
La evaluación ultrasonográfica es una de las técnicas adecuadas para la realización del diagnóstico de tenosinovitis. Stratico et al. (2014) describe hallazgos ecográficos comunes, tales como la presencia de coágulos de fibrina, distención de la vaina sinovial y adherencias entre la vaina y el tendón flexor digital profundo, además de la remodelación ósea del borde medial del sustentáculo tali. En el presente caso fueron visibles coágulos de fibrina en la vaina sinovial, además de distensión severa y efusión sinovial; sin embargo, a diferencia del mencionado reporte, se encontró una disminución en la ecogenicidad (hipoecogénico) a nivel de la cabeza medial del TFDP, y no se evidenciaron hallazgos que sugirieran irregularidades periósticas. Por otro lado, Archer et al. (2004), mencionan que en tres de cinco casos encontraron hipoecogenicidad en el TFDP asociada a tenosinovitis traumática; así mismo, describen que la lesión se extiende hacia distal y con una mayor severidad.

El tratamiento debe enfocarse en medicamentos que contribuyan a la regeneración sinovial, tales como el ácido hialurónico y glicosaminoglicanos polisulfatados, además de las infiltraciones intrasinoviales con factores de crecimiento para promover la cicatrización y regeneración de las fibras tendinosas (Giraldo y Salinas, 2010). Este tipo de terapias pueden ser complementadas con infiltraciones de corticoides que permitan el efecto antinflamatorio, además de un plan de rehabilitación con ejercicio progresivo $\mathrm{y}$ fisioterapia para disminuir el proceso inflamatorio y mejorar el movimiento de la articulación (Minshall y Wright, 2012). El presente caso se hizo a la par del tratamiento farmacológico la terapia regenerativa con infiltraciones de ácido hialurónico y fisioterapia (ultrasonido y terapia laser) para ejercer un efecto fibrinolítico que permitiera la disminución de la efusión sinovial e inhibiera la agregación inflamatoria a nivel local. 
Los lavados intrasinoviales son una de las opciones recomendadas en el enfoque terapéutico de esta patología. Chan et al. (1997) indicaron que los lavados permanentes son una alternativa al tratamiento convencional, lo cual permite la instilación de volúmenes adecuados de líquido y la eliminación de exudados inflamatorios, fibrina y restos celulares. En el presente caso, el paciente no respondió adecuadamente al tratamiento convencional con antiinflamatorios de tipo esteroidal, ácido hialurónico y sulfato de atropina, por lo que se decidió realizar lavados sinoviales continuos con dimetil sulfóxido DMSO al 10\% durante tres días para lograr un efecto de atrapamiento de radicales libres, generar una acción antinflamatoria y eliminar los detritos inflamatorios presentes (Straticò, 2014).

\section{Literatura Citada}

1. Archer DC, Clegg PD, Edwards GB. 2004. Septic tenosynovitis of the tarsal sheath of an Arab gelding and suspected sepsis of the lateral digital flexor tendon subsequent to bacterial peritonitis. Vet Rec 155:485-489. doi: 10.1136/vr.155.16.485

2. Ashdown R, Done SH. 2011. Color atlas of veterinary anatomy the horse. Vol. 2. The horse. Mosby. 368 p.

3. Barr AR, Dyson SJ, Barr FJ, O'Brien JK. 1995. Tendonitis of the deep digital flexor tendon associated with tenosynovitis of the digital sheath in the horse. Equine Vet J 27: 348-355. doi: 10.1111/ j.2042-3306.1995.tb04069.x

4. Baxte GM, Stashak TS, Belknap JK, Parks A. 2011. Manual of equine lameness. Chichester: Wiley-Blackwell. 480 p.
5. Baxter GM. 2011. Adams and Stashak's lameness in horses. $6^{\text {th }} \mathrm{ed}$. John Wiley. $1280 \mathrm{p}$.

6. Budras KD, Sack WO, Röck S. 2008. Anatomy of the horse. $5^{\text {th }}$ ed. Schlütersche. $199 \mathrm{p}$.

7. Butle J, Colles CN, Dyson SJ, Kold SE, Poulos PW. 2008. Clinical radiology of the horse. $3^{\text {rd }}$ ed. Wiley-Blackwel. $760 \mathrm{p}$.

8. Cauvin E. 2003. Tenoscopy and bursoscopy: In: Rose M, Dyson S (eds). Diagnosis and management of lameness in the horse. Philadelphia: Saunders. p 260-265.

9. Chan CC, Munroe GA. 1997. Septic tenosynovitis and focal osteomyelitis of the lateral proximal sesamoid bone in a Thoroughbred gelding. Vet Rec 141: 147150. doi: 10.1136/vr.141.6.147

10. Giraldo L, Salinas L. 2010. Aproximación artroscópica de tenosinovitis traumática de la vaina sinovial tarsiana: reporte de caso. Rev CES Med Zootec 5: 77-85.

11. Minshall GJ, Wright IM. 2012. Synoviocoeles associated with the tarsal sheath: description of the lesion and treatment in 15 horses. Equine Vet J 44: 71-75. doi: 10.1111/j.2042-3306.2010.00360.x

12. Ross MW, Dyson SJ. 2003. Lameness in the horse. USA: Elsevier Science. $1140 \mathrm{p}$.

13. Straticò P, Varasano V., Suriano R, Sciarrini C, Petrizzi L. 2014. Traumatic septic tenosynovitis of the tarsal sheath with fragmentation of the sustentaculum tali: surgical treatment and outcome in 3 horses. Equine Vet J 34: 538-543. doi: 10.1016/j.jevs.2013.09.010 